\title{
Utility of doppler derived middle cerebral artery: peak systolic velocity and pulsatility index in prediction of perinatal outcomes of IUGR pregnancies
}

\author{
Surbhi Gupta*, Sunita hemani Sharma, Renuka mundliya, Lata Ratanoo
}

Department of Obstetrics and Gynecology, SMS Medical College and Group of Hospitals, Jaipur, Rajasthan, India

Received: 01 July 2016

Accepted: 05 August 2016

*Correspondence:

Dr. Surbhi Gupta,

E-mail: drsurbhi2610@hotmail.com

Copyright: (c) the author(s), publisher and licensee Medip Academy. This is an open-access article distributed under the terms of the Creative Commons Attribution Non-Commercial License, which permits unrestricted non-commercial use, distribution, and reproduction in any medium, provided the original work is properly cited.

\begin{abstract}
Background: To determine the association of Middle cerebral artery-peak systolic velocity (MCA-PCV) and perinatal outcome among IUGR fetuses. Longitudinal changes occurring in MCA-pulsatality index and MCA-PSV in IUGR fetuses were studied and the performance of MCA-PI, MCA-PSV in IUGR fetuses was compared.

Methods: Hospital based cohort study of 40 IUGR fetuses (gestation age 28-36 weeks, Estimated fetal weight <10th percentile, Umbilical artery PI $>95$ th percentile) in whom MCA-PSV values were obtained on three or more occasions from the time of admission till delivery depending upon period of gestation and severity of IUGR. For analysis purpose two groups were made of twenty patients each depending upon MCA-PSV.

Results: All the fetuses (100\%) in group B (i.e. with abnormal MCA-PSV) had adverse perinatal outcome in the form of either mortality or major neonatal complication consisting of Newborn intensive care unit stay $\geq 14$ days, requirement of artificial ventilation or presence of intraventricular hemorrhage, respiratory distress or sepsis. Specificity of abnormal MCA-PSV was found to be $100 \%$ in predicting adverse perinatal outcome. When followed longitudinally, in the three fetuses having fetal death, the PSV showed an initial increase in velocity followed by a fall prior to demise, thus suggesting that it could be a pre-terminal event

Conclusions: Fetal MCA-PSV appears to be a reliable indicator of adverse perinatal outcome in growth restricted fetuses thus implying that abnormality in MCA-PSV warrants stringent monitoring. Serial Doppler examinations of fetal MCA-PSV provide better information than does a single measurement.
\end{abstract}

Keywords: Intra uterine growth restriction, Middle cerebral artery-peak systolic velocity, Middle cerebral arteryPulsatility index, Color Doppler, Intra uterine death and Newborn intensive care unit stay

\section{INTRODUCTION}

Intrauterine growth restriction (IUGR) is considered as a major contributor to perinatal morbidity and mortality due to a high incidence of hypoxemia, acidemia, intrauterine fetal demise, intra-partum fetal morbidity and operative deliveries, stillbirth, neonatal morbidity and mortality and cerebral palsy. ${ }^{1-3}$ There are multiple causes of IUGR which either can be maternal, fetal and placental. IUGR affects 3-10\% all pregnancies.

In IUGR due to placental insufficiency, there is a redistribution of blood from the periphery to the vital organs like brain. These changes are studied by Doppler study of blood flow patterns in uterine artery, umbilical artery, middle cerebral artery and ductus venosus. 
Doppler studies reveal changes of hypoxia at least one week before the non-stress test or the biophysical profile. It has therefore become the gold standard in the management of the growth-restricted fetuses and aids in making decision regarding appropriate timing of delivery in an attempt to prevent perinatal and hopefully long term damage. $^{4-6}$

Umbilical artery (UA) and middle cerebral artery are the most frequently studied vessels.

This study aimed to determine the association of Middle cerebral artery- peak systolic velocity (MCA-PCV) and perinatal morbidity and mortality among IUGR fetuses. Longitudinal changes occurring in MCA- pulsatality index and MCA-PSV in IUGR fetuses were also studied. This study also compared the performance of MCA-PI, MCA-PSV and umbilical artery absent or reversed end diastolic flow velocity in prediction of perinatal morbidity and mortality in these fetuses.

\section{METHODS}

This study is a hospital based cohort study done after approval by the Ethics committee.40 pregnant women with singleton pregnancy with IUGR and who fulfilled the following inclusion criteria were enrolled in the study-

Period of gestation $\geq 28$ weeks and $<36$ weeks, estimated fetal weight $<10^{\text {th }}$ percentile and Umbilical arterypulsatility index $>95^{\text {th }}$ percentile.

Women with fetuses showing congenital anomalies were excluded from the study. Informed written consent was obtained from the mothers prior to enrollment.

These women were further subjected to Doppler studies including UA-PI, MCA-PI and MCA-PSV using standard techniques. MCA-PSV and MCA-PI values were considered abnormal when they were above the $95^{\text {th }}$ percentile or below the $5^{\text {th }}$ percentile for MCA-PSV range and MCA-PI range.

For analysis purpose two groups were made of 20 patients each.

Group A i.e. IUGR patients with normal MCA PSV.

Group B i.e. IUGR patients with abnormal MCA PSV.

Doppler studies of UA and MCA were repeated depending on period of gestation and severity of IUGR.

Ultrasongraphy along with Doppler study were performed using two systems- ALOKA (Alpha -6 MO2552 LI) or Toshiba (SSA-510A) by transabdominal method using trans-abdominal probe of 2-5 Mhz. The MCA was visualized in transverse axial view of fetal head at a slightly caudal plane than one used for biparietal diameter measurements. All recordings were obtained in the absence of fetal breathing and fetal movement.

Indications for delivery were- Abnormal fetal heart tracing, absent diastolic or reversal of diastolic flow in umbilical artery, worsening of maternal condition like preeclampsia, gestational age $>34$ weeks in patients with high resistance diastolic flow and amniotic fluid index less than 5 .

Steroids were administered (Inj. Betamethasone $12 \mathrm{mg}$ i.m. stat followed by repeat dose after 24 hours) to all the women between 28 to 36 weeks to enhance fetal lung maturity. Induction of labour was done depending upon the Bishop's Score. Emergency caesarean section was done whenever fetal distress developed. Elective caesarean was done for associated fetal and obstetric indications.

Neonatal outcomes which were assessed included Gestational age at birth. Birth weight of newborn, APGAR score at $5 \mathrm{~min}$, Stay in NICU, Condition on discharge from NICU and Adverse perinatal outcome. Adverse perinatal outcome was described by the following end points-perinatal or Neonatal mortality and major neonatal complications like intra- ventricular hemorrhage, respiratory distress or sepsis or prolonged NICU stay for $>14$ days.

Data gathered was then statistically analyzed using microsoft excel and SPSS software. Difference in proportion was analyzed using chi-square tests while difference in mean was inferred by unpaired " $t$ " test. Significance level for tests was determined as 95\% (P $<0.05)$.

\section{RESULTS}

The two groups were comparable when age, religion, residence, literacy, socioeconomic status and gravida status was considered as shown in Table 1.

$30 \%$ women in group A and $40 \%$ women in group B were hypertensive. $70 \%$ women in group A and $85 \%$ in group B were underweight. $90 \%$ women in both groups had moderate anemia.

In women with Doppler study showing normal MCAPSV, $15 \%$ delivered at gestational age <36 weeks and $85 \%$ delivered $\geq 36$ weeks, mean age at delivery was 36.10 weeks. When the MCA-PSV was abnormal $75 \%$ women had delivery at $<36$ weeks reducing the mean age at delivery to 34.20 weeks. The difference in the mean gestational age at the time of delivery was statistically significant $(\mathrm{p}<0.001)$. Thus suggesting that abnormal MCA Doppler waveforms warrant earlier pregnancy termination. 
Table 1: Baseline characteristics.

\begin{tabular}{|c|c|c|c|}
\hline Characteristic & Group-A (Normal MCA PSV) ( $\mathrm{N}=20$ ) & Group-B (Abnormal MCA PSV) $(\mathrm{N}=20)$ & P-Value \\
\hline $\begin{array}{l}\text { Mean Age (in } \\
\text { years) }\end{array}$ & $24.30 \pm 3.57$ & $25.00 \pm 3.40$ & NS \\
\hline Urban residency & $12(60 \%)$ & $14(70 \%)$ & NS \\
\hline Literacy rate & $13(65 \%)$ & $12(60 \%)$ & NS \\
\hline \multicolumn{4}{|c|}{ Socio-economic status } \\
\hline Lower class & $9(45 \%)$ & $5(25 \%)$ & NS \\
\hline Middle class & $8(40 \%)$ & $12(60 \%)$ & NS \\
\hline Primigravida & $12(60 \%)$ & $10(50 \%)$ & NS \\
\hline
\end{tabular}

Table 2: Neonatal outcomes.

\begin{tabular}{|c|c|c|c|}
\hline Outcome & $\begin{array}{l}\text { Group-A (Normal } \\
\text { MCA PSV) }(\mathbf{N}=20)\end{array}$ & $\begin{array}{l}\text { Group-B (Abnormal MCA } \\
\text { PSV) }(\mathbf{N}=20)\end{array}$ & P-Value \\
\hline Mean gestational age at delivery (in weeks) & $36.10 \pm 0.91$ & $34.20 \pm 1.36$ & $<0.001$ \\
\hline Intra uterine death & $0(0 \%)$ & $3(15 \%)$ & - \\
\hline Live birth & $20(100 \%)$ & $17(85 \%)$ & NS \\
\hline Nursery observation & $12(60 \%)$ & $0(0 \%)$ & \multirow[t]{2}{*}{0.00003467} \\
\hline NICU admission & $8(40 \%)$ & $17(100 \%)$ & \\
\hline Mean duration of stay in NICU (in days) & $9.37 \pm 6.37$ & $14.64 \pm 8.47$ & $<0.05$ \\
\hline Prolonged NICU stay (>14 days) & $2(10 \%)$ & $16(94.1 \%)$ & 0.00003601 \\
\hline Neonatal Mortality & $0(0 \%)$ & $1(5.9 \%)$ & - \\
\hline Birth weight of newborn (in kg) & $1.99 \pm 0.38$ & $1.54 \pm 0.35$ & $<.001$ \\
\hline APGAR score(at 5 Min) $<7$ days & $14(70 \%)$ & $20(100 \%)$ & 0.007 \\
\hline
\end{tabular}

Table 3: Doppler parameters.

\begin{tabular}{|c|c|c|c|c|c|c|c|}
\hline Doppler parameter & $\begin{array}{l}\text { Adverse } \\
\text { perinatal } \\
\text { outcome } \\
(\mathrm{n}=22)\end{array}$ & $\begin{array}{l}\text { No adverse } \\
\text { perinatal } \\
\text { outcome } \\
(\mathrm{n}=18)\end{array}$ & P - value & $\begin{array}{l}\text { Sensitivity } \\
(\%)\end{array}$ & $\begin{array}{l}\text { Specificity } \\
(\%)\end{array}$ & $\begin{array}{l}\text { Positive } \\
\text { predictive } \\
\text { value }\end{array}$ & $\begin{array}{l}\text { Negative } \\
\text { predictive } \\
\text { value }\end{array}$ \\
\hline $\begin{array}{l}\text { Abnormal MCA - } \\
\text { PSV }\left(>95^{\text {th }} \text { or }<5^{\text {th }}\right. \\
\text { percentile })\end{array}$ & 20 & 0 & $<0.05$ & $90.91 \%$ & $100 \%$ & $100 \%$ & $90 \%$ \\
\hline $\begin{array}{l}\text { Abnormal MCA-PI } \\
\left(>95^{\text {th }} \text { or }<5^{\text {th }}\right. \\
\text { percentile })\end{array}$ & 21 & 2 & $<0.05$ & $95.45 \%$ & $88.89 \%$ & $91.3 \%$ & $94.12 \%$ \\
\hline
\end{tabular}

$70 \%$ of women in group A and $60 \%$ women in group B developed oligo hydramnios (AFI <5) and had to be terminated $85 \%$ of women in group A and $75 \%$ in group $\mathrm{B}$ had cesarean section. There were 5 vaginal deliveries out of 20 in group B of which 3 were IUFD and the other 2 were delivered vaginally because of patient refusal for cesarean section and both had adverse perinatal outcome. In group A of 20 women there were 3 vaginal deliveries, 2 of them were severe IUGR and advised LSCS but the patient refused, out of these two one had NICU stay $>14$ days however there were no perinatal mortalities in group A.
Table 4: Association of MCA PSV with MCA PI and adverse perinatal outcome.

\begin{tabular}{|c|c|c|c|c|}
\hline MCA & $\begin{array}{l}\text { Normal } \\
\text { PI (17) }\end{array}$ & $\begin{array}{l}\text { Abnormal } \\
\text { PI (23) }\end{array}$ & $\begin{array}{l}P \\
\text { value }\end{array}$ & $\begin{array}{l}\text { Adverse } \\
\text { perinatal } \\
\text { outcome }\end{array}$ \\
\hline $\begin{array}{l}\text { Normal } \\
\text { PSV (20) }\end{array}$ & $\begin{array}{l}12 \\
(60 \%)\end{array}$ & $8(40 \%)$ & \multirow{2}{*}{0.025} & $2(10 \%)$ \\
\hline $\begin{array}{l}\text { Abnormal } \\
\text { PSV (20) }\end{array}$ & $5(25 \%)$ & $15(75 \%)$ & & $\begin{array}{l}20 \\
(100 \%)\end{array}$ \\
\hline
\end{tabular}


Neonatal outcomes in terms of live birth, IUFD, birth weight (in $\mathrm{kg}$ ), APGAR score at 5 min, mean duration and prolonged stay $(>14$ days) in NICU and associated neonatal mortality are shown in Table 2.

The association of abnormal MCA Doppler with adverse perinatal outcome was found to be significant for both PSV and PI (P-value $<0.05$ for both). Specificity for abnormal MCA-PSV was found to be $100 \%$ which implies that presence of abnormality of MCA-PSV is associated with high chances of adverse perinatal outcome. Specificity of MCA-PI was lower (88.89\%) than MCA-PSV suggesting that MCA-PSV is a better marker of fetal hemodynamic status in fetal growth restriction than PI which is the frequently studied marker Table 3.

The Doppler parameters comparing abnormal MCA PSV with abnormal MCA PI and adverse perinatal outcome is shown in Table 4.

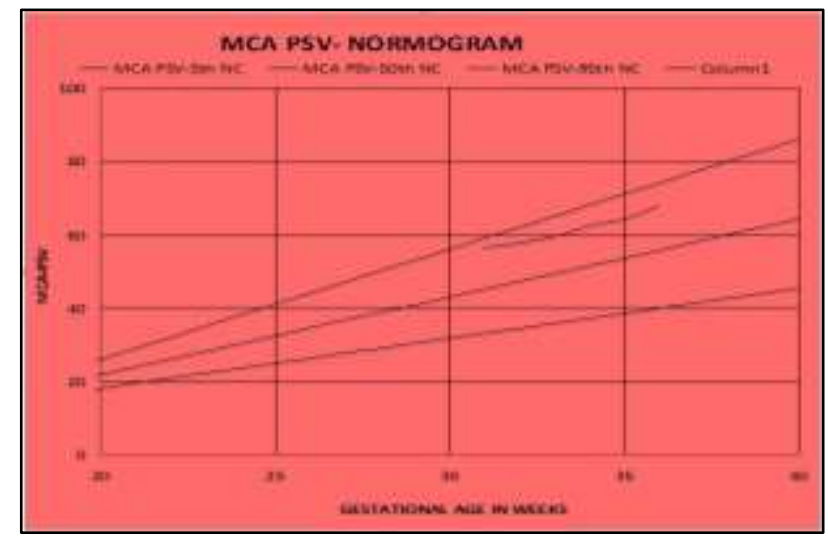

Figure 1: MCA-PSV nomogram of IUGR patient with normal delivery.

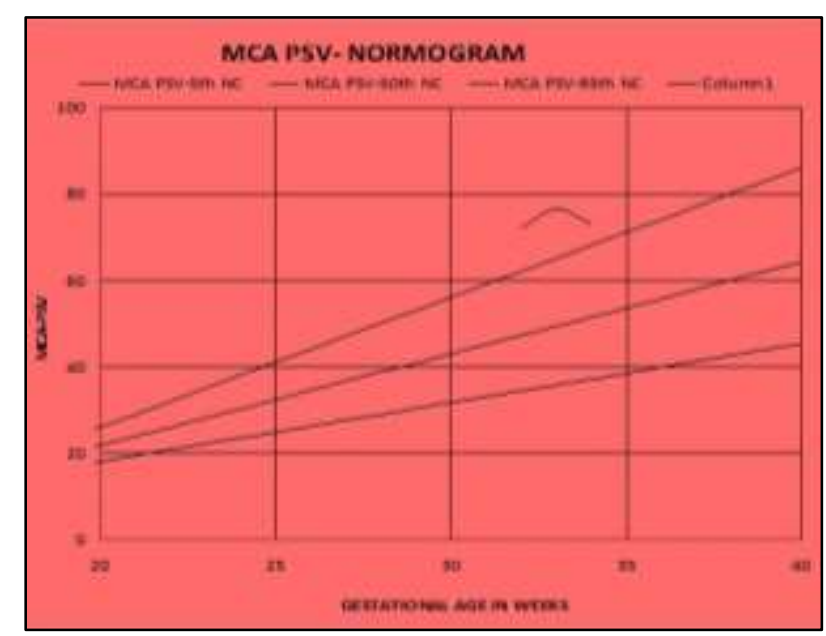

Figure 2: MCA-PSV nomogram of IUGR patient with Intra-Uterine death.

In patients with normal MCA-PSV $60 \%$ had normal PI and $40 \%$ had abnormal PI. However only $10 \%$ had adverse perinatal outcome. Among women with abnormal PSV $100 \%$ had adverse perinatal outcome despite $25 \%$ of them showing normal PI.

MCA-PSV showed an increase with gestational age in most of the study subjects (Figure 1). In the fetuses having fetal death, the PSV showed an initial increase in velocity beyond the $95^{\text {th }}$ percentile followed by a fall prior to demise (Figure 2), however, the value remained above the upper limit of normal.

In the patients who had at least three recordings of Doppler parameters prior to delivery, association of a fall in MCA-PSV was studied as a predictor of fetal death. All 3 IUGR fetuses who had intrauterine demise had such fall in MCA-PSV prior to fetal death. Thus, the specificity of fall of MCA-PSV for predicting fetal death was high.

\section{DISCUSSION}

In this study, the longitudinal assessment of MCA-PI and MCA-PSV in IUGR fetuses was done and it was found that the MCA waveforms PI and PSV show changes with worsening of fetal condition but MCA-PSV predicts imminent perinatal mortality more accurately than MCA PI. Changes in MCA-PSV and MCA-PI also vary according to the gestational age.

In a healthy fetus, MCA-PI falls with advancing gestational age and this decrease probably reflects a decreasing vascular resistance with increasing gestational age. With placental insufficiency, there is an increase in brain circulation causing increased diastolic flow resulting in decrease in $S / D$ ratio. When fetus is overstressed, the brain sparing effect is lost and the MCA-PI increases. With increased severity, the MCAPSV increases, as a consequence of increased left cardiac output. The nadir of MCA-PI is reached in 14 days or more before fetal compromise. ${ }^{7}$ The middle cerebral artery peak systolic velocity increases in severely growth restricted fetuses and it remains elevated until a few hours prior to fetal demise. ${ }^{8}$

Mari $G$ et al had observed that in IUGR fetuses, the trends of MCA-PSV and MCA-PI provide more clinical information than does a single measurement. ${ }^{9}$

In our longitudinal monitoring of MCA-PSV an increase was seen with gestational age. In the three fetuses with intrauterine fetal demise, the PSV showed an initial increase in velocity beyond the $95^{\text {th }}$ percentile followed by a fall prior to demise, however the value remained above the upper limit of normal. These trends were consistent with those of Mari G et al. ${ }^{9}$

Specificity of fall of MCA-PSV for predicting fetal death was quite high suggesting that it could be a preterminal event and termination of pregnancy may be contemplated when this situation is documented to prevent perinatal 
mortality. Oczan T et al have suggested that MCA-PSV is a good predictor of perinatal mortality in IUGR fetuses. Rizzo et al also found an increase in MCA-PSV in IUGR which remains elevated until a few hours prior to fetal demise. ${ }^{10,11}$

Fetuses which showed abnormalities in longitudinal studies of MCA-PSV had a poor APGAR score and a longer duration of stay in NICU as compared to those with normal MCA-PSV. Hemlata D et al also found that those with abnormal MCA-PSV were twice likely for NICU admission. Nalini Y et al found that 35\%cases with abnormal Umbilical artery and Middle cerebral artery Doppler waveforms required NICU admission. ${ }^{12,13}$

Changes in MCA-PI were not as consistent as those of MCA-PSV. MCA-PI was normal in 5 patients with abnormal PSV which finally had adverse perinatal outcome. Mari $\mathrm{G}$ et al found an abnormal PI in most fetuses with a tendency towards normalization before delivery or fetal demise but in few fetuses no change or decrease was observed.

\section{CONCLUSION}

IUGR cases should be monitored with tests of fetal wellbeing like non-stress test, bio-physical profile and serial Doppler evaluation of umbilical artery. When the umbilical artery waveforms are abnormal further Doppler studies of other vessels like middle cerebral artery, aortic isthmus and ductus venosus become necessary.

Current study demonstrates that Doppler study of MCAPSV should be used in the surveillance together with the currently used MCA-PI so as to decide the optimal time for delivery permitting maximum maturity with minimal fetal hypoxia or acidosis and hence optimizing good fetal outcome.

PSV when serially examined showed progressive increase with a tendency to slightly decrease prior to fetal demise. The specificity of such fall was $100 \%$. MCA-PI on the other hand presented an inconsistent pattern. MCA-PSV has shown increased specificity in predicting adverse perinatal outcome and so its use is recommended along with MCA-PI in IUGR fetuses.

\section{Funding: No funding sources}

Conflict of interest: None declared

Ethical approval: Not required

\section{REFERENCES}

1. Kady S, Gardosi I. Perinatal mortality and fetal growth restriction. Clin Obstet Gynaecol. 2004; 18:397-410.
2. Jarvis S, Glinianaia SV, Torrioli $\mathrm{MG}$, Platt MJ, Miceli M, Jouk PS, et al. Surveillance of Cerebral Palsy in Europe (SCPE) collaboration of European Cerebral Palsy Registers. Cerebral palsy and intrauterine growth in single births. Lancet. 2003;362:1106-11.

3. Barker DJ. Adult consequences of fetal growth restriction. Clin Obstet Gynecol. 2006;49:270-83.

4. Gonzalez JM, Stamilio DM, Ural S, Macones GA, Odibo AO. Relationship between abnormal fetal testing and adverse perinatal outcomes in intrauterine growth restriction. Am J Obstet Gynecol. 2007;196(5):e48-e51.

5. Padmagirison R, Rai L. Fetal Doppler versus NST as predictors of adverse perinatal outcome in severe preeclampsia and fetal growth restriction. J Obstet Gynecol. 2006;56:134-8.

6. Fouron JC. The unrecognized physiological and clinical significance of the fetal aortic isthmus. Ultrasound Obstet Gynecol. 2003;22:441-7.

7. Arduini D, Rizzo G, Romaini G. Changes of pulsatility index from fetal vessel preceding the onset of late decelerations in growth retarded fetuses. Obstet Gynecol. 1992;79:605-10.

8. American College of Obstetricians and Gynecologists. ACOG Practice Bulletin: Intrauterine Growth Restriction. Number 12. Washington, DC: American College of Obstetricians and Gynecologists, 2000.

9. Mari G, Hanif F, Kruger M, Cosmi E, SantolayaForgas J, Treadwell MC. Middle cerebral artery peak systolic velocity: a new Doppler parameter in the assessment of growth restricted fetuses. Ultrasound Obstet Gynecol. 2007;29:310-16.

10. Ozcan T, Sbracia M, d'Ancona RL, Copel JA, Mari G. Arterial and venous Doppler velocimetry in the severely growth-restricted fetus and associations with adverse perinatal outcome. Ultrasound Obstet Gynecol. 1998;12:39-44.

11. Rizzo G, Capponi A, Arduini D, Romanini C. The value of fetal arterial, cardiac and venous flow in predicting $\mathrm{pH}$ and blood gases in umbilical blood at cordocentesis in growth retarded fetuses. Br J Obstet Gynaecol. 1995;102:963-9.

12. Dhand H, Kumar KH, Anupama D. Middle Cerebral Artery Doppler Indices Better Predictor for Fetal Outcome in IUGR. The Journal of Obstetrics and Gynecology of India. 2011:166-171.

13. Nalini YL, Jyothirmayi K, Reddy CM. Fetal outcome in relation with Colour Doppler study of middle cerebral artery and umblical artery in intrauterine growth restriction. Int $\mathrm{J}$ Res Med Sci. 2015;3(7):1721-5.

Cite this article as: Gupta $\mathrm{S}$, Sharma $\mathrm{SH}$, Mundliya R, Ratanoo L. Utility of doppler derived middle cerebral artery: peak systolic velocity and pulsatility index in prediction of perinatal outcomes of IUGR pregnancies. Int J Reprod Contracept Obstet Gynecol 2016;5:3017-21. 